\title{
ĐƯờnG CONG HUẤN LUYỆN TRONG PHẪU THUẠTT VAN HAI LÁ ÍT XÂM LẤN QUA ĐƯờnG MỞ NGỰC NHỎ BÊN PHẢI
}

\section{Võ Tuấn Anh*, Nguyễn Hoàng Định*}

\section{TÓM TẮT}

Đây là nghiên cứu theo dõi dọc tiến cứu kết hợp hồi cứu các bệnh nhân được phẫu thuật van hai lá ít xâm lấn qua đường mở ngực nhỏ bên phải tại bệnh viện Đại học Y Dược TP.Hồ Chí Minh từ tháng 8 năm 2014 đến tháng 1 năm 2019. Thời gian chạy máy tim phổi nhân tạo, kẹp động mạch chủ, thời gian thở máy và thời gian nằm hồi sức được đánh giá xu hướng theo năm. Số lượng ca phẫu thuật cần thiết để vượt qua đường cong huấn luyện được đánh giá bằng biểu đồ tổng tích lũy của thất bại kĩ thuật (Cumulative Sum - CUSUM). Trong thời gian nghiên cứu, có 204 trường hợp phẫu thuật van hai lá ít xâm lấn qua đường mở ngực nhỏ bên phải. Tuổi trung bình của bệnh nhân là $48.5 \pm 24.9$, nhóm tuổi 51 - 60 tuổi chiếm tỉ lệ cao nhất. Lý do nhập viện thường gặp nhất là khó thở khi gắng sức $(94,1 \%)$. Tỉ lệ biến chứng kĩ thuật là 5,4\%. Thời gian tuần hoàn ngoài cơ thể, thời gian kẹp động mạch chủ, thời gian thở máy và thời gian nằm hồi sức giảm dần theo thời gian và theo số lượng ca mổ tích lũy. Số lượng bệnh nhân cần để vượt qua được đường cong huấn luyện là 75 đến 100 trường hợp.

\section{SUMMARY}

Our retro-prospective study reviewed patients underwent minimally cardiac surgery at the University Medical Center, Ho Chi Minh city from 04/2018 to 01/2019. Cardiopulmonary bypass time, aortic clamp time, mechanical ventilation time and ICU time was assessed throughout the years. The number of patients required to overcome the learning curve was assessed with the Cumulative Sum failure analysis. 204 patients underwent minimally invasive mitral valve surgery. The mean age was $48.5 \pm 24$. The most common chief complaint was dyspnea on exertion (94.1\%). Technical failure rate was $5,4 \%$. Cardiopulmonary bypass time, aortic clamp time, mechanical ventilation time and ICU time reduced with time and the cumulative cases performed. The number of patients required to overcome the learning curve was $75-100$ patients.

Key words: Learning curve, minimally invasive cardiac surgery, mitral valve.

\section{MỞ ĐẦU}

Phẫu thuật van hai lá ít xâm lấn qua đường mở ngực nhỏ bên phải có những bước phát triển tốt trong những năm gần đây và đã trở thành đường tiếp cận thường quy cho bệnh lý van hai lá ở nhiều trung tâm, đặc biệt là ở Châu Âu, với kết quả ngắn hạn và dài hạn rất tốt [5],[10]. Tuy vậy, các báo cáo với kết quả tốt thường xuất phát từ các trung tâm có lượng bệnh nhân lớn và giàu kinh nghiệm trong kĩ thuật này. Bác sĩ phẫu thuật của các trung tâm bắt đầu triển khai có thể ngần ngại khi bắt đầu triển khai kĩ thuật này vì vấn đề đường cong huấn luyện. Đã có 1 số tác giả báo cáo và bàn luận về vấn đề này đa số chỉ dừng lại

\footnotetext{
* Đại học Y Dược TP.Hồ Chí Minh

Ngưòi chịu trách nhiệm khoa họ: PGS.TS. Nguyễn Hoàng Định Ngày nhận bài: 01/07/2019 - Ngày Cho Phép Đăng: 20/07/2019 Phản Biện Khoa học: PGS.TS. Đặng Ngọc Hùng GS.TS. Lê Ngoc Thành
} 
ở mức độ ý kiến chuyên gia, không có nhiều bằng chứng hỗ trợ [2].

Vấn đề chính đặt ra với các bác sĩ phẫu thuật khi bắt đầu thực hiện kĩ thuật này là câu hỏi lợi ích tiềm năng của phẫu thuật van hai lá ít xâm lấn qua đường mở ngực nhỏ bên phải (giảm thời gian thở máy, giảm thời gian nằm hồi sức, bớt đau và nguy cơ nhiễm trùng vết mổ thấp hơn [3]) có lớn hơn so với tỉ lệ biến chứng khi bắt đầu áp dụng một kĩ thuật mới hay không. Trên thực tế, có một số chuyên gia cho rằng đường cong huấn luyện của phẫu thuật tim ít xâm lấn khá dài và vì vậy không nên triển khai đại trà kĩ thuật này [1]. Hiện nay, đã có những nghiên cứu với thiết kế tốt và số lượng bệnh nhân đủ lớn đã được thực hiện và có những kết quả đáng tin cậy [4].

Chúng tôi thực hiện nghiên cứu này nhằm đánh giá xu hướng thay đổi theo thời gian và số lượng tích lũy ca mổ của những biến số quan trọng trong phẫu thuật van hai lá ít xâm lấn, từ đó rút ra được số lượng bệnh nhân cần thiết để vượt qua được đường cong huấn luyện của loại hình kĩ thuật mới này trong điều kiện của Trung tâm Tim mạch bệnh viện Đại học Y Dược TP. Hồ Chí Minh.

\section{II. ĐỐI TƯợNG VÀ PHƯƠNG PHÁP NGHIÊN CỨU}

\section{1. Đối tượng}

\subsection{Phương pháp}

\section{Phương pháp nghiên cứu}

Đây là nghiên cứu tiến cứu kết hợp theo dõi dọc.

\section{Tiêu chuẩn chọn bệnh}

+ Người bệnh mắc bệnh van hai lá có chỉ định phẫu thuật theo hướng dẫn của Hiệp hội Tim mạch Hoa Kì (ACC/AHA) [6].
+ Được phẫu thuật ít xâm lấn qua đường mở ngực nhỏ bên phải.

$+\mathrm{EF}>40 \%$, tuổi $\leq 80$ tuổi, PAPs $<60$ $\mathrm{mmHg}$ [7].

+ Chức năng thất phải tốt (TAPSE $>18$ mm, Tricuspid Valve Plane Systolic Excursion Độ di động của mặt phẳng vòng van ba lá trong thời kì tâm thu) [9].

\section{Tiêu chuẩn loại trừ}

+ Có bệnh lý tim mạch khác cần can thiệp đi kèm: Bệnh lý van động mạch chủ, bệnh lý động mạch vành, bệnh lý tim bẩm sinh.

+ Hở van động mạch chủ trung bình.

+ Tắc hoặc hẹp động mạch chủ bụng, động mạch chậu, động mạch đùi hai bên.

+ Huyết khối hệ thống tĩnh mạch chủ.

+ Tiền căn phẫu thuật lồng ngực bên $(\mathrm{P})$ trước đây.

+ Bệnh nhân đã từng phẫu thuật tim qua đường giữa xương ức.

+ Hở van ba lá, thông liên nhĩ lỗ thứ phát và rung nhĩ không thuộc tiêu chí loại trừ.

Đánh giá biến thiên theo thời gian và số lượng ca mổ tích lũy của các biến số quan trọng

- Khảo sát sự biến thiên của các biến số sau theo năm bằng hồi quy tuyến tính với spline dành cho thời gian (Spline model):

+ Thời gian chạy máy tim phổi nhân tạo.

+ Thời gian kẹp động mạch chủ

+ Thời gian thở máy.

+ Thời gian nằm hồi sức.

- So sánh từng nhóm 50 bệnh nhân phẫu thuật tích lũy theo thời gian để đánh giá sự khác nhau về: 
+ Thời gian chạy máy tim phổi nhân tạo.

+ Thời gian kẹp động mạch chủ

+ Thời gian thở máy.

+ Thời gian nằm hồi sức.

+ Tỉ lệ biến chứng về kĩ thuật.

Đánh giá số lượng bệnh nhân cần thiết để vượt qua đường cong huấn luyện

Để đánh giá số bệnh nhân cần thiết để vượt qua đường cong huấn luyện, chúng tôi sử dụng biểu đồ tích lũy (Cumulative Sum - CUSUM) theo phương pháp của Holzhey và cộng sự [3]. CUSUM được định nghĩa theo công thức: $\mathrm{Sn}=$ $\Sigma(X i-p 0)$, trong đó $X i=0$ nếu thành công và $\mathrm{Xi}=1$ nếu thất bại về mặt kĩ thuật và $\mathrm{p} 0$ là giá trị tham chiếu, ở đây là tỉ lệ thất bại chấp nhận được. Theo Holzhey và một số các tác giả khác $[8$, 11]các tỉ lệ cho phẫu thuật van hai lá ít xâm lấn được lựa chọn như sau:

- p0: Tỷ lệ thất bại chấp nhận được, p0 = $0,1(10 \%)$

- p1: Tỉ lệ thất bại không chấp nhận được, $\mathrm{p} 1=0,2(20 \%)$

- Alpha: sai lầm loại I, chọn alpha = 0.05 (5\%).

- Beta: sai lầm loại II, chọn beta = 0.05 (5\%).

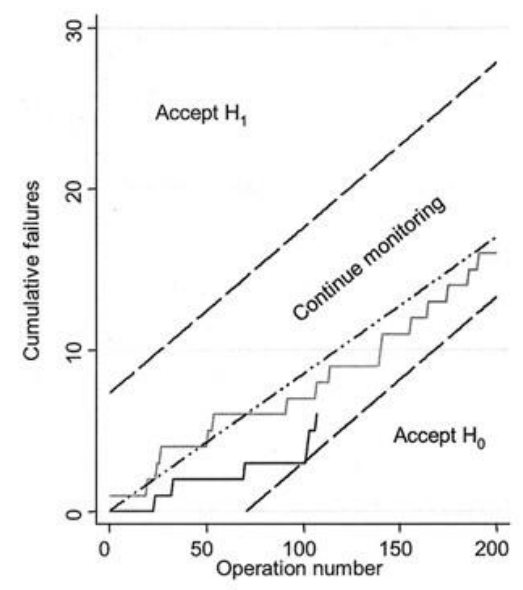

Hình 1. Đường biểu diễn CUSUM[8]
Từ đó chúng tôi tính ra đường giới hạn trên và dưới theo công thức được mô tả trong bài báo của Rogers và cộng sự và vẽ được biểu đồ tích lũy số trường hợp thất bại về kĩ thuật theo định nghĩa ở trên và diễn giải như sau:

+ Khi đường tích lũy vượt lên trên đường giới hạn trên: kết luận tỷ lệ thất bại tăng cao quá mức và không chấp nhận được.

+ Khi đường tích lũy vượt xuống dưới đường giới hạn dưới: kết luận tỷ lệ thất bại thấp hơn tỷ lệ thất bại chấp nhận được.

+ Khi đường tích lũy đi giữa đường giới hạn trên và dưới: chưa kết luận được, cần tiếp tục theo dõi.

Thất bại về mặt kĩ thuật được tính khi có một trong những biến số sau:

- Tử vong chu phẫu hoặc tử vong sớm trong vòng 30 ngày.

- Chuyển mổ hở.

- Hở cạnh van hai lá hơn mức trung bình sau phẫu thuật

- Hở van hai lá hơn mức trung bình sau phẫu thuật.

- Phẫu thuật lại vì bất cứ lý do gì.

- Tổn thương bó mạch đùi.

- Nhiễm trùng vết mổ.

- Bóc tách động mạch chủ.

- Tai biến mạch máu não không hồi phục.

\section{KẾT QUẢ}

Từ tháng 8 năm 2014 đến tháng 1 năm 2019, có tổng cộng 204 bệnh nhân thỏa tiêu chí chọn vào được đưa vào nghiên cứu, trong đó có 107 bệnh nhân nữ và 97 bệnh nhân nam. Tuổi trung bình của bệnh nhân là $48.5 \pm 24.9$, nhóm 
tuổi 51 - 60 tuổi chiếm tỉ lệ cao nhất. BMI trung bình là 21.9
Lý do nhập viện thường gặp nhất là khó thở khi gắng sức $(94,1 \%)$.

Bảng 1. Phân bố bệnh nhân theo cơ chế bệnh sinh

\begin{tabular}{lcc}
\hline Cơ chế bệnh sinh & Số lượng & Tỉ lệ \% \\
\hline Hậu thấp & 91 & 44,6 \\
Thoái hóa & 110 & 53,9 \\
Viêm nội tâm mạc nhiễm trùng & 3 & 1,5 \\
\hline
\end{tabular}

Về phương pháp phẫu thuật, có 114 bệnh nhân được thay van, chiếm tỉ lệ $56 \%$ và 90 trường hợp được sửa van, chiếm 44\%. Trong các bệnh nhân thay van, 71 bệnh nhân được thay van cơ học $(62 \%)$ và 43 bệnh nhân được thay van sinh học $(38 \%)$.

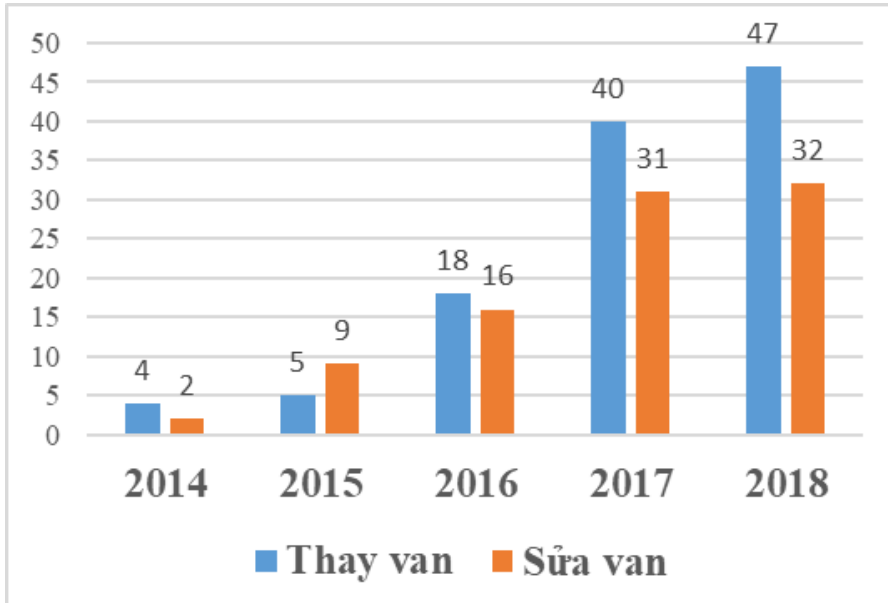

Biểu đồ 1. Phân bố bệnh nhân thay van và sủa van theo thời gian

Bảng 2. Tỉ lệ tai biến và biến chứng về kĩ thuật

Biến chứng $\quad$ Số lưọng $\quad$ Tỉ lệ \% $(\mathrm{n}=204)$

Tử vong chu phẫu

1

Hỗ trợ tuần hoàn ngoài cơ thể (ECMO)

0

0

Nhiễm trùng vết mổ

0

0

Hẹp động mạch đùi

2

1

Hẹp tĩnh mạch đùi

0

0

Tai biến mạch máu não không hồi phục

0

0

Phẫu thuật lại do chảy máu

5

2,4 
Phẫu thuật lại do van hai lá

Liệt cơ hoành phải

Chuyển mổ hở
0

0

3
0

0

1,5

\section{TỔNG}

11

$5,4 \%$

Để phân tích về đường cong huấn luyện, chúng tôi xem xét xu hướng thay đổi của thời gian chạy máy, thời gian kẹp động mạch chủ, thời gian nằm thở máy và thời gian nằm hồi sức qua các mốc thời gian từ 2014 đến 2018 (5 năm) cũng như đánh giá sự khác biệt về các thời gian này theo nhóm 50 trường hợp để đánh giá sự khác biệt khi số lượng phẫu thuật của 1 phẫu thuật viên tăng lên.

\section{Thời gian chạy máy, thời gian kẹp động mạch chủ}

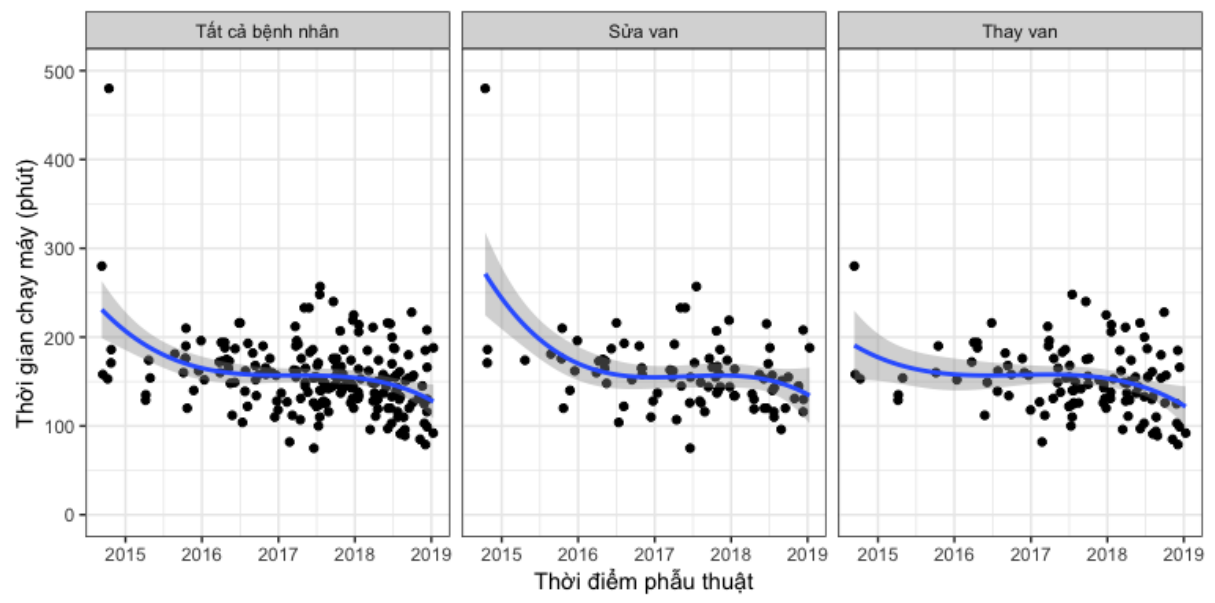

Biểu đồ 2. Phân bố thời gian chạy máy tim phổi nhân tạo theo năm

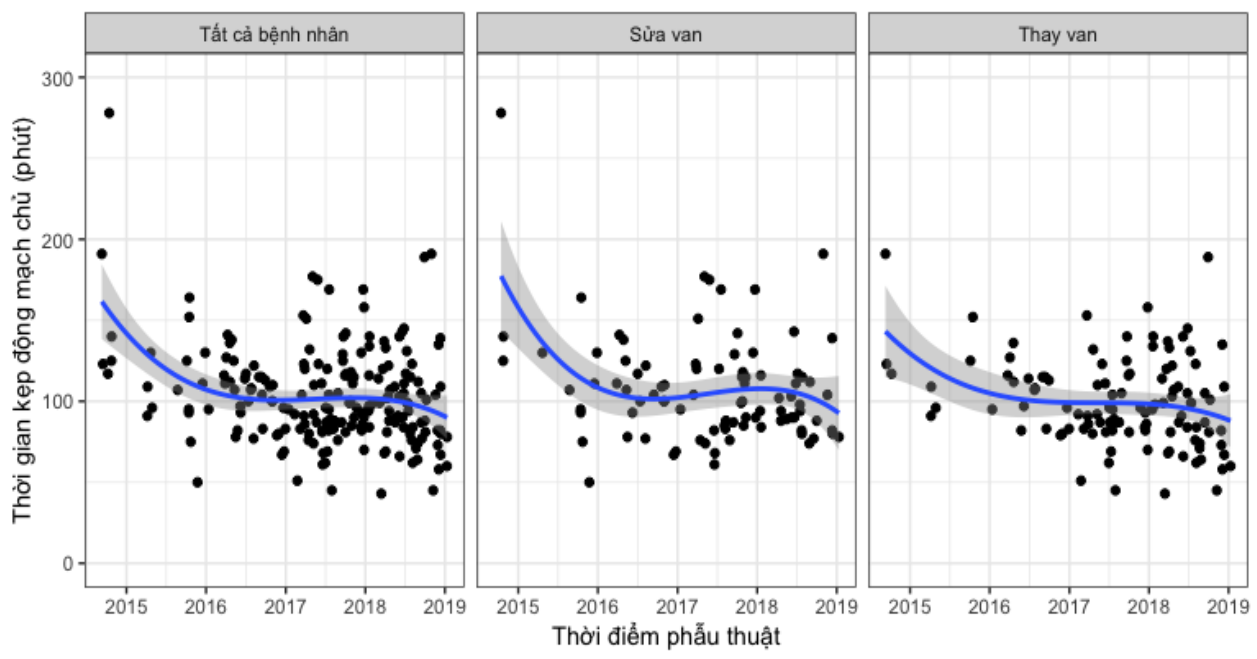

Biểu đồ 3. Phân bố thời gian chạy kẹp động mạch chủ theo năm 
Thời gian thở máy, thời gian nằm hồi sức

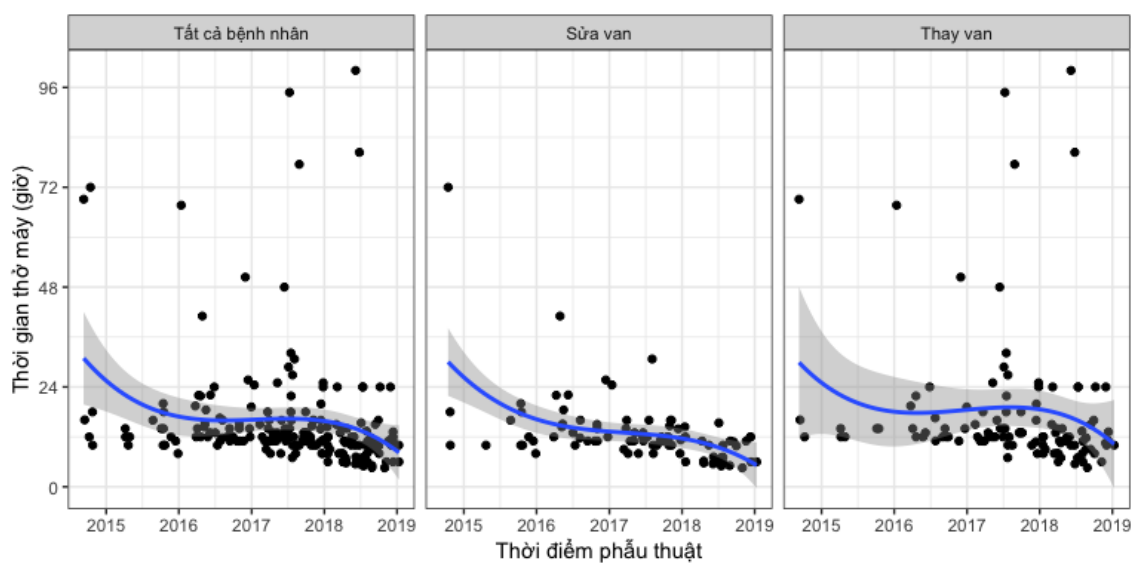

Biểu đồ 4. Phân bố thời gian thở máy theo năm
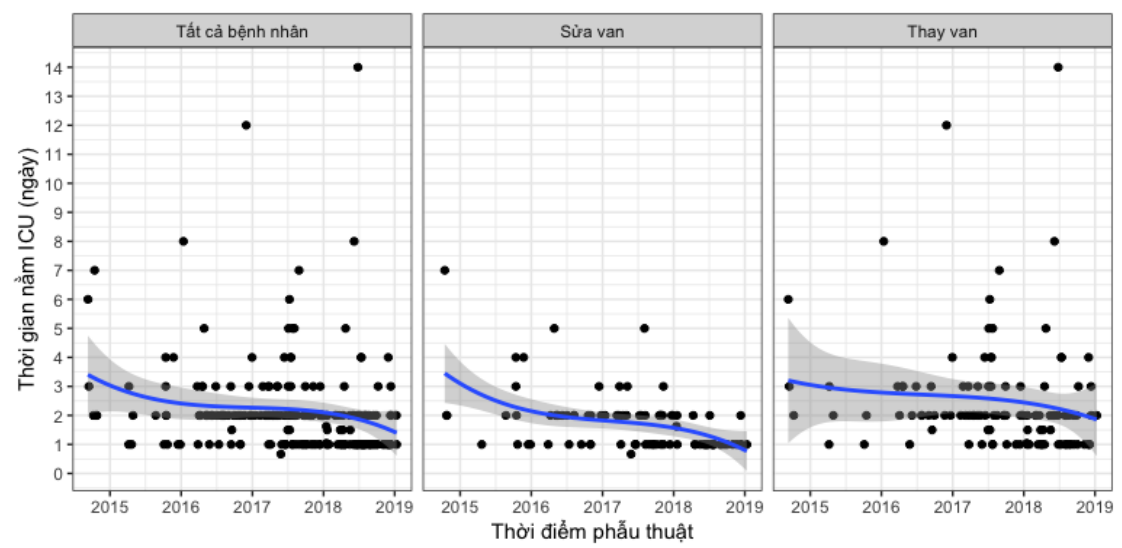

Biểu đồ 5. Phân bố thời gian nằm hồi sức theo năm

So sánh thông số theo mỗi nhóm 50 ca mổ

Bảng 3. Thông số phẫu thuật phân chia theo nhóm 50 ca mổ

\begin{tabular}{lccccc}
\hline Thông số & $\mathbf{1 - 5 0}$ & $\mathbf{5 1 - 1 0 0}$ & $\mathbf{1 0 1 - 1 5 0}$ & $\mathbf{1 5 1 - 2 0 0}$ & $\mathbf{p}$ \\
\hline Thời gian kẹp ĐM chủ & 115,1 & $104,8(29,5)$ & $99,2(24,8)$ & $95,5(29,6)$ & $\mathbf{0 . 0 0 0 3}^{\mathbf{a}}$ \\
(phút) & $(33,3)$ & & & & \\
Thời gian chạy tim phổi & 173,9 & $155,6(39,5)$ & 151,9 & 143,3 & $\mathbf{0 . 0 0 0 9}^{\mathbf{a}}$ \\
nhân tạo (phút) & $(53,3)$ & & $(31,6)$ & $(36,6)$ & \\
Thời gian thở máy (giờ) & 18,0 & $16,8(10,4)$ & 10.4 & 8,7 & $\mathbf{0 . 0 0 0 1}^{\mathbf{a}}$ \\
& $(14,2)$ & & $(7,2)$ & $(4,9)$ & \\
Thò̀i gian nằm ICU (giờ) & 56,4 & $61,3(43,8)$ & $46,8(23,5)$ & $35,7(19,2)$ & $\mathbf{0 . 0 0 0 1}^{\mathbf{a}}$ \\
& $(35,7)$ & & & & \\
Phẫu thuật kèm theo & $14,0 \%$ & $28,0 \%$ & $30,0 \%$ & $30,0 \%$ & $\mathbf{0 . 0 3 2 6}^{\mathbf{b}}$ \\
Biến chứng chu phẫu & $\mathbf{1 6 , 0 \%}$ & $\mathbf{2 0 , 0 \%}$ & $\mathbf{9 , 0 \%}$ & $\mathbf{8 , 0 \%}$ & $\mathbf{0 . 0 4 9 2}^{\mathbf{b}}$ \\
\hline
\end{tabular}

a Phép kiểm Kruskal Wallis

${ }^{b}$ Phép kiểm Chi bình phương 


\section{Phân tích CUSUM}

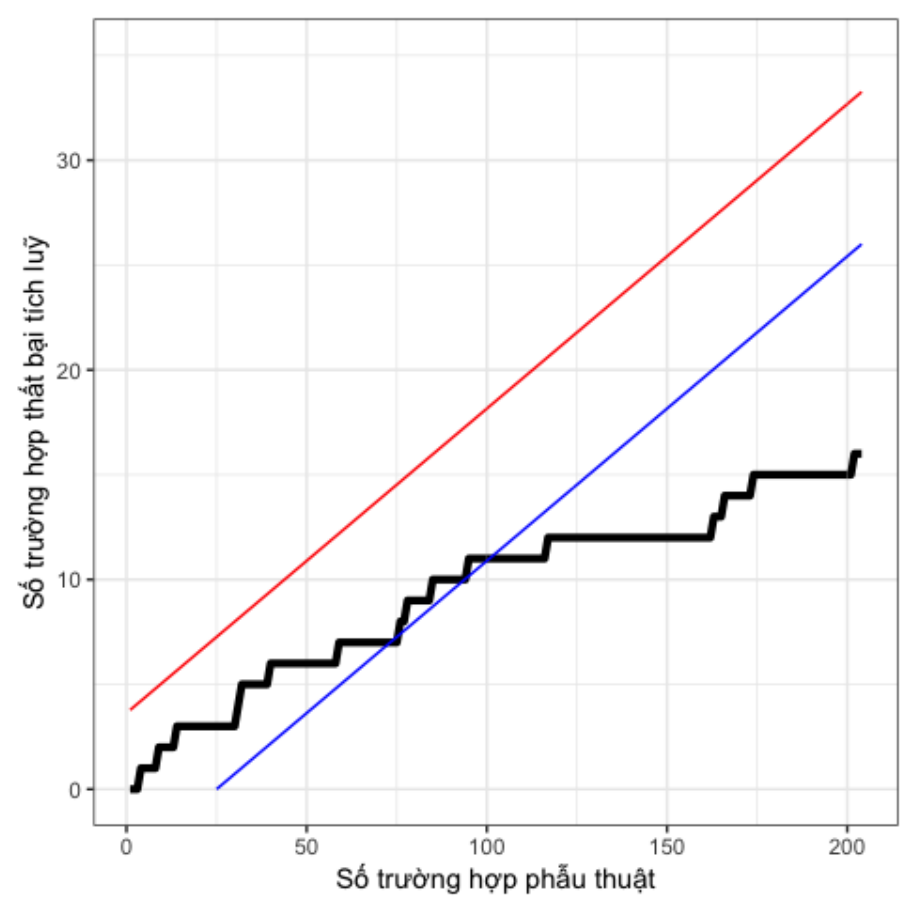

Biểu đồ 6. Phân tích CUSUM cho đường cong huấn luyện

Đường biểu diễn số trường hợp thất bại về mặt kĩ thuật tích lũy (đường màu đen) bắt đầu tiệm cận với đường giới hạn dưới tại 75 trường hợp và vượt xuống dưới đường giới hạn dưới tại vị trí 100 trường hợp. Không có thời điểm nào đường màu đen vướt quá đường giới hạn trên.

Như vậy, chúng tôi nhận thấy cần từ 75 đến 100 trường hợp phẫu thuật van hai lá ít xâm lấn để có thể vượt qua được đường cong huấn luyện và có số trường hợp thất bại về mặt kĩ thuật giảm xuống có ý nghĩa.

\section{BÀN LUẬN}

Bên cạnh chọn lựa bệnh nhân kĩ lưỡng trong giai đoạn đầu, hiệu quả của phẫu thuật tim ít xâm lấn cũng chịu ảnh hưởng lớn từ đường cong huấn luyện. Nhằm đảm bảo an toàn cho bệnh nhân, bác sĩ phẫu thuật cần vượt qua số lượng ca mổ nhất định, cũng như đảm bảo số lượng phẫu thuật đều đặn theo thời gian.
Trong nghiên cứu của chúng tôi, thời gian kẹp động mạch chủ, thời gian chạy máy tim phổi nhân tạo, thời gian thở máy và thời gian nằm hồi sức giảm dần theo thời gian. Khi chia số lượng bệnh nhân thành từng nhóm 50 trường hợp theo thời gian, chúng tôi phân lập thành 4 nhóm bệnh nhân khác nhau. Khi so sánh các nhóm này với nhau về các tiêu chí: Thời gian kẹp động mạch chủ, thời gian chạy máy tim phổi nhân tạo, thời gian thở máy, thời gian nằm hồi sức, chúng tôi nhận thấy các tiêu chí này đều giảm dần theo thời gian, và sự khác biệt này có ý nghĩa thống kê. Bên cạnh đó, tỉ lệ phẫu thuật đi kèm cũng tăng lên và tỉ lệ biến chứng xuất hiện cũng giảm đi có ý nghĩa thống kê. Tương tự, tác giả Nissen và cộng sự [7] cũng ghi nhận cần có đường cong huấn luyện để cải thiện các tiêu chí về thời gian kẹp động mạch chủ và thời gian chạy máy tim phổi nhân tạo. 


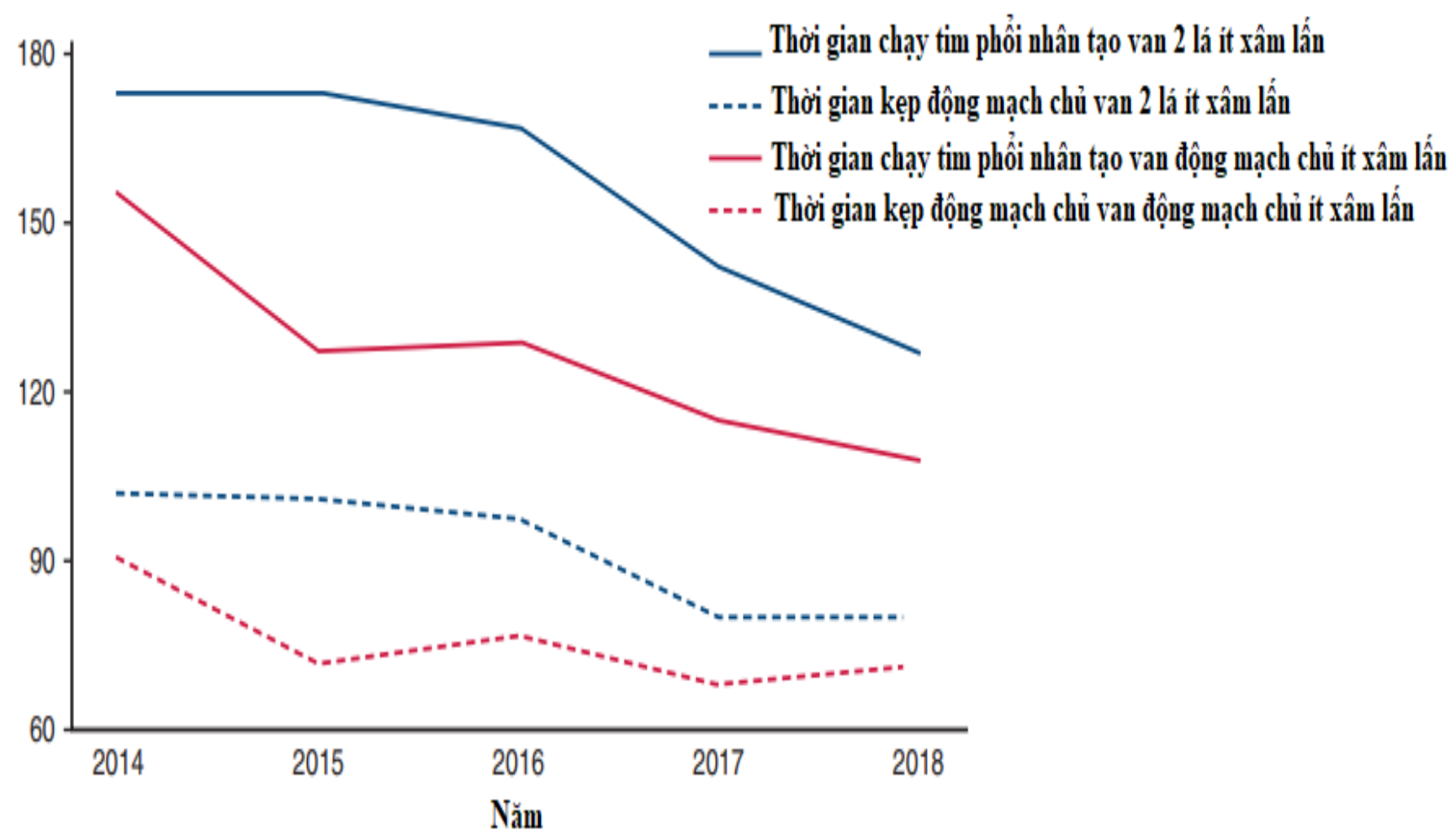

Hình 2.Thời gian kẹp động mạch chủ và thời gian chạy tim phổi nhân tạo của phẫu thuật van hai lá ít xâm lấn và phẫu thuật van động mạch chủ í xâm lấn

Nguồn: Nissen (2018) [7]

Tác giả Holzhey và cộng sự [4] đã thực hiện một nghiên cứu đơn trung tâm trên 3895 trường hợp phẫu thuật van hai lá ít xâm lấn đơn thuần hoặc có phẫu thuật kèm theo (phẫu thuật van ba lá, đốt điện điều trị rung nhĩ) trong giai đoạn 17 năm. Trong nghiên cứu này, các tác giả nhận thấy đối với từng bác sĩ phẫu thuật, kết quả sẽ tốt hơn theo thời gian khi số lượng bệnh nhân được phẫu thuật tăng lên. Tỉ lệ biến chứng sau mổ (chuyển mổ hở, mổ lại do chảy máu, tai biến mạch máu não, nhồi máu cơ tim cấp, hội chứng cung lượng tim thấp và tử vong) chiếm khoảng $25 \%$ trong giai đoạn đầu, sau đó giảm xuống còn $10 \%$ sau 250 trường hợp phẫu thuật. Đặc biệt đối với chảy máu sau mổ, tỉ lệ biến chứng giảm từ $8,2 \%$ xuống còn $1,9 \%$ sau 300 trường hợp phẫu thuật, tương tự như vậy đối với chuyển mổ hở.

Khi đánh giá từng phẫu thuật viên, Holzhey và cộng sự [4] ghi nhận số lượng bệnh nhân cần thiết cho một bác sĩ phẫu thuật để có tỉ lệ tai biến, biến chứng giảm đi có ý nghĩa thống kê là 75 đến 125 trường hợp phẫu thuật. Bên cạnh đó có những phẫu thuật viên được đánh giá là xuất sắc với tỉ lệ biến chứng rất thấp ngay từ khi khởi đầu và cũng có những phẫu thuật viên không cải thiện tỉ lệ biến chứng sau 1 thời gian dài. 

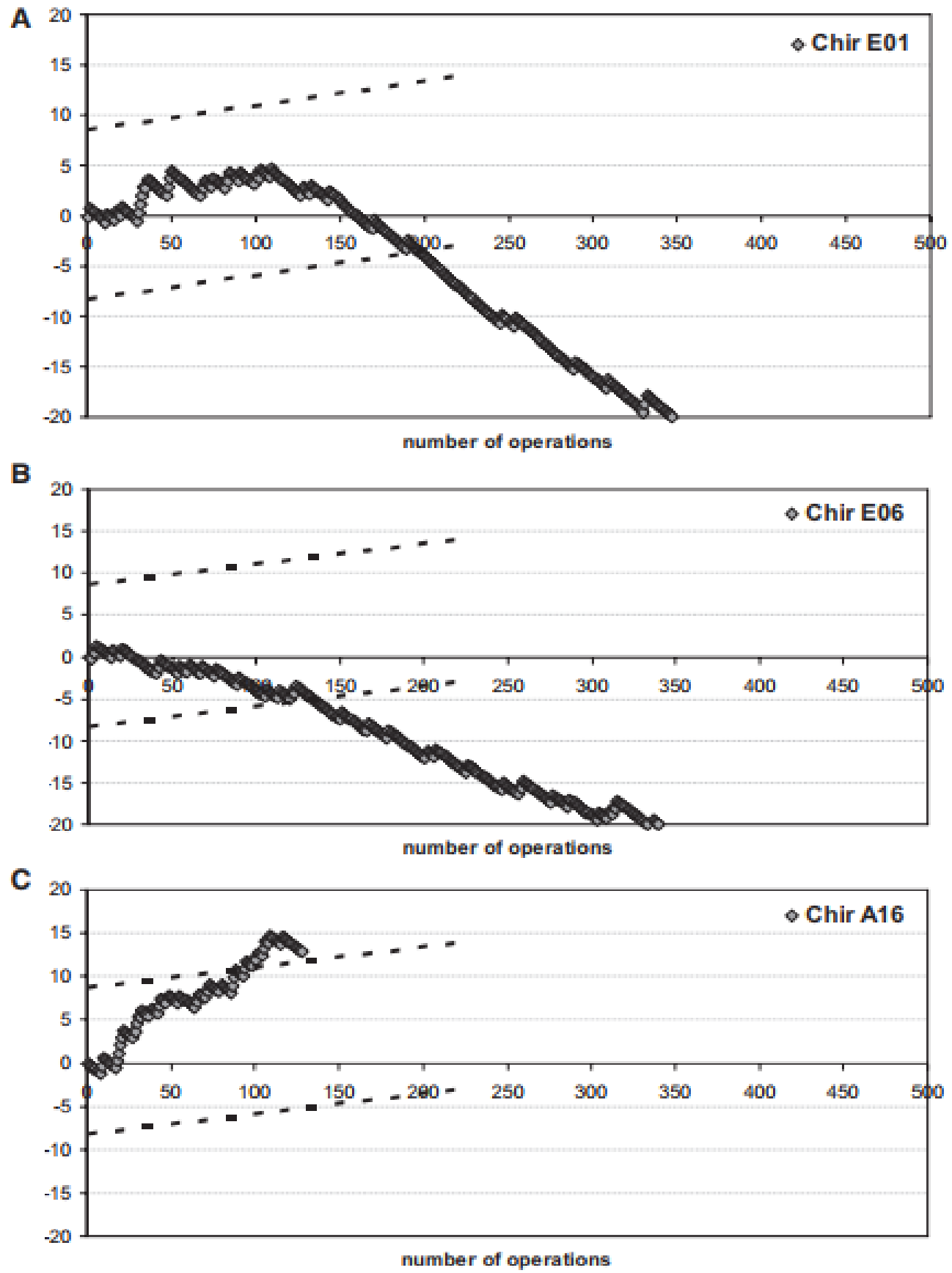

Hình 3. Đuờng cong huấn luyện biểu diễn bằng hiệu số của số luợng biến chưng thực tế và số lượng biến chứng mong đợi theo thời gian [4]
A. Đường cong huấn luyện kinh điển
B. Đường cong huấn luyện của bác sĩ phẫu thuật xuất sắc.
C. Đường cong huấn luyện của bác sĩ phẫu thuật không tốt.

Bên cạnh số lượng bệnh nhân phẫu thuật, các tác giả còn đánh giá ảnh hưởng của tần suất phẫu 
thuật van ít xâm lấn đến các biến chứng của phẫu thuật và cho thấy nếu một bác sĩ phẫu thuật thực hiện ít nhất 2 phẫu thuật/tuần thì kết quả phẫu thuật sẽ tốt hơn. Tuy vậy, tần suất phẫu thuật nhiều hơn 2 trường hợp/tuần lại không cải thiện đáng kể kết quả phẫu thuật.

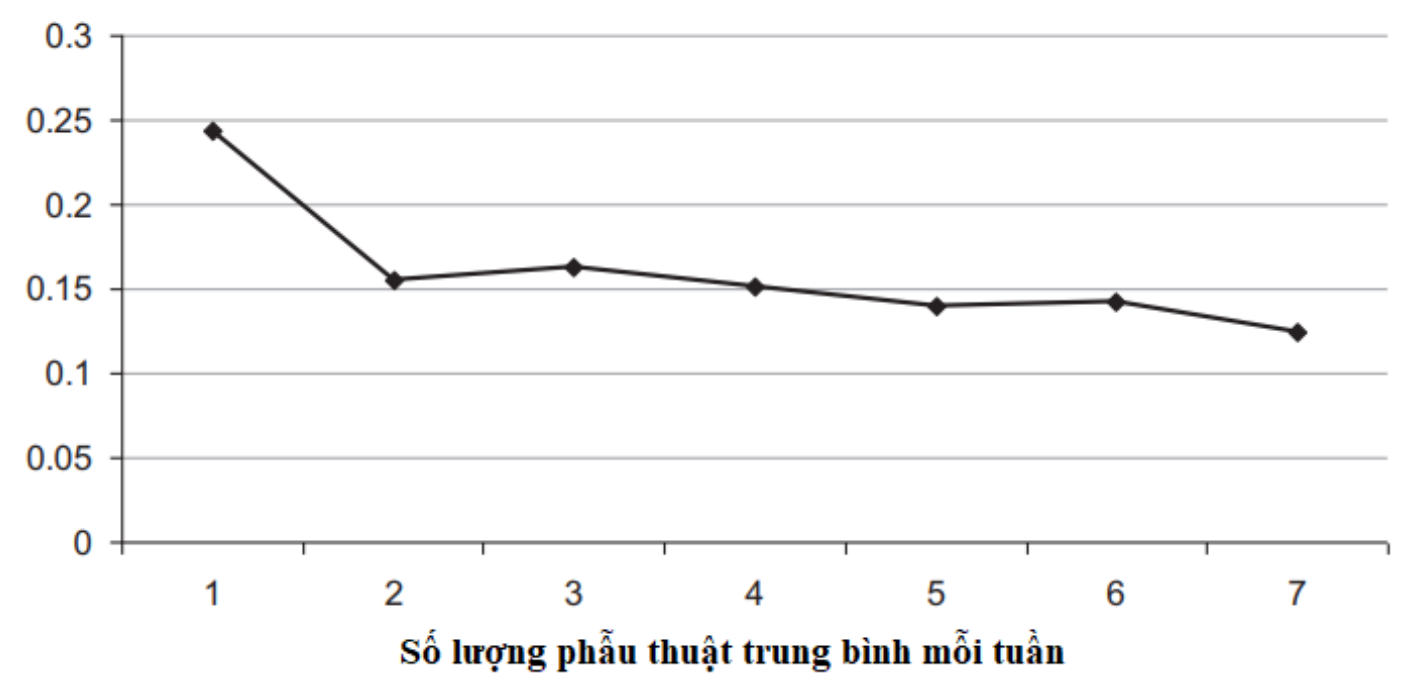

Hình 4.7. Tương quan giữa tỉ lẹ biến chưng và số lương phẫu thuật trung bình mỗi tuần[4]

Các tác giả kết luận phẫu thuật van hai lá ít xâm lấn qua đường mở ngực phải có đường cong huấn luyện kéo dài. Mặc dù có sự biến đổi giữa các bác sĩ phẫu thuật khác nhau, số lượng phẫu thuật van hai lá cần thiết để vượt qua đường cong huấn luyện cũng tương đối lớn. Bên cạnh đó, các tác giả cũng khuyến cáo chỉ nên triển khai phẫu thuật van hai lá ít xâm lấn ở những trung tâm có số lượng phẫu thuật van hai lá lớn.

Tương tự như Holzhey và cộng sự, chúng tôi thực hiện phân tích CUSUM và nhậN được kết quả 75 đến 100 trường hợp. Như vậy, với kết quả của chúng tôi và các nghiên cứu trên thế giới cho thấy đường cong huấn luyện đóng vai trò quan trọng trong quyết định kết quả của phẫu thuật van hai lá ít xâm lấn. Về số lượng bệnh nhân để vượt qua đường cong huấn luyện, chúng tôi cho rằng Holzhey và cộng sự có những khuyến cáo phù hợp với con số từ 75 đến 100 trường hợp phẫu thuật, con số này thay đổi tùy theo kinh nghiệm phẫu thuật tim của bác sĩ phẫu thuật. Bên cạnh đó, cần thực hiện ít nhất
2 trường hợp phẫu thuật/tuần nhằm duy trì kết quả đạt được.

\section{KẾT LUẬN}

Phẫu thuật van hai lá ít xâm lấn có đường cong huấn luyện tương đối dài là 75 đến 100 trường hợp. Dù có thể có sự khác biệt giữa những phẫu thuật viên khác nhau, loại phẫu thuật này đòi hỏi một số lượng bệnh nhân không nhỏ để tỉ lệ biến chứng kĩ thuật giảm đi có ý nghĩa và có thể chấp nhận được, đồng nghĩa bác sĩ phẫu thuật đã vượt qua đường cong huấn luyện. Qua đó, chúng tôi cũng nhận thấy phẫu thuật van hai lá ít xâm lấn nên được triển khai tại những trung tâm lớn, có số lượng phẫu thuật van hai lá nhiều và cần chọn lựa bệnh đơn giản, ít yếu tố nguy cơ trong giai đoạn ban đầu, khi bác sĩ đã vượt qua được đường cong huấn luyện, có thể mở rộng chỉ định đối với những trường hợp phức tạp hơn. 


\section{TÀI LIỆU THAM KHẢO}

1. A. D. Caffarelli, R. C. Robbins (2004) "Will minimally invasive valve replacement ever really be important?". Curr Opin Cardiol, 19, (2), 123-7.

2. P. J. Charland, T. Robbins, E. Rodriguez, W. L. Nifong, R. W. Chitwood, Jr. (2011) "Learning curve analysis of mitral valve repair using telemanipulative technology". J Thorac Cardiovasc Surg, 142, (2), 404-10.

3. D. C. Cheng, J. Martin, A. Lal, A. Diegeler, T. A. Folliguet, L. W. Nifong, P. Perier, E. Raanani, J. M. Smith, J. Seeburger, V. Falk (2011) "Minimally invasive versus conventional open mitral valve surgery: a meta-analysis and systematic review". Innovations (Phila), 6, (2), 84-103.

4. D. M. Holzhey, J. Seeburger, M. Misfeld, M. A. Borger, F. W. Mohr (2013) "Learning minimally invasive mitral valve surgery: a cumulative sum sequential probability analysis of 3895 operations from a single high-volume center". Circulation, 128, (5), 483-91.

5. P. Modi, A. Hassan, W. R. Chitwood, Jr. (2008) "Minimally invasive mitral valve surgery: a systematic review and meta-analysis". Eur $J$ Cardiothorac Surg, 34, (5), 943-52.

6. R. A. Nishimura, C. M. Otto, R. O. Bonow, B. A. Carabello, J. P. Erwin, 3rd, L. A. Fleisher, H. Jneid, M. J. Mack, C. J. McLeod, P. T. O'Gara, V. H. Rigolin, T. M. Sundt, 3rd, A. Thompson (2017) "2017 AHA/ACC Focused Update of the 2014 AHA/ACC
Guideline for the Management of Patients With Valvular Heart Disease: A Report of the American College of Cardiology/American Heart Association Task Force on Clinical Practice Guidelines". Circulation, 135, (25), e1159-e1195.

7. A. P. Nissen, S. Nguyen, J. Abreu, T. C. Nguyen (2018) "The first 5 years: Building a minimally invasive valve program". $J$ Thorac Cardiovasc Surg.

8. C. A. Rogers, B. C. Reeves, M. Caputo, J. S. Ganesh, R. S. Bonser, G. D. Angelini (2004) "Control chart methods for monitoring cardiac surgical performance and their interpretation". J Thorac Cardiovasc Surg, 128, (6), 811-9.

9. E. Schmid, J. N. Hilberath, G. Blumenstock, P. S. Shekar, S. Kling, S. K. Shernan, P. Rosenberger, M. Nowak-Machen (2015) "Tricuspid annular plane systolic excursion (TAPSE) predicts poor outcome in patients undergoing acute pulmonary embolectomy". Heart Lung Vessel, 7, (2), 151-158.

10. J. Seeburger, M. A. Borger, V. Falk, T. Kuntze, M. Czesla, T. Walther, N. Doll, F. W. Mohr (2008) "Minimal invasive mitral valve repair for mitral regurgitation: results of 1339 consecutive patients". Eur J Cardiothorac Surg, 34, (4), 760-5.

11. X. Wu, W. Wei, Y. He, H. Qin, F. Qi (2019) "Analysis of the Learning Curve in Mitral Valve Replacement Through the Right Anterolateral Minithoracotomy Approach: A Surgeon's Experience with the First 100 Patients". Heart Lung Circ, 28, (3), 471-476. 